Article

\title{
Applying OGC Standards to Develop a Land Surveying Measurement Model
}

\author{
Ioannis Sofos ${ }^{1, *}$, Vassilios Vescoukis ${ }^{1}$, Athanasios Gkegkas ${ }^{1}$ and Elisavet Tsilimantou ${ }^{2}$ \\ 1 School of Rural and Surveying Engineering, National Technical University of Athens (NTUA), \\ Athens 15780, Greece; v.vescoukis@cs.ntua.gr (V.V.); agegasnet@gmail.com (A.G.) \\ 2 School of Chemical Engineering, National Technical University of Athens (NTUA), Athens 15780, Greece; \\ eltsilim@mail.ntua.gr \\ * Correspondence: gs.sofos@gmail.com; Tel.: +30-690-656-3947
}

Academic Editors: Bernd Resch and Wolfgang Kainz

Received: 29 October 2016; Accepted: 24 February 2017; Published: 28 February 2017

\begin{abstract}
The Open Geospatial Consortium (OGC) is committed to developing quality open standards for the global geospatial community, thus enhancing the interoperability of geographic information. In the domain of sensor networks, the Sensor Web Enablement (SWE) initiative has been developed to define the necessary context by introducing modeling standards, like 'Observation \& Measurement' (O\&M) and services to provide interaction like 'Sensor Observation Service' (SOS). Land surveying measurements on the other hand comprise a domain where observation information structures and services have not been aligned to the OGC observation model. In this paper, an OGC-compatible, aligned to the 'Observation and Measurements' standard, model for land surveying observations has been developed and discussed. Furthermore, a case study instantiates the above model, and an SOS implementation has been developed based on the $52^{\circ}$ North SOS platform. Finally, a visualization schema is used to produce 'Web Map Service (WMS)' observation maps. Even though there are elements that differentiate this work from classic 'O\&M' modeling cases, the proposed model and flows are developed in order to provide the benefits of standardizing land surveying measurement data (cost reducing by reusability, higher precision level, data fusion of multiple sources, raw observation spatiotemporal repository access, development of Measurement-Based GIS (MBGIS)) to the geoinformation community.
\end{abstract}

Keywords: surveying; observations standard; OGC; measurements; model; SOS

\section{Introduction}

The Internet has provided the necessary technical tools, prototypes and services that have made it possible to largely revolutionize many activities ranging from research to daily life activities over the past few years [1,2]. Open data access and standardized service provision have contributed to the spread of sharing concepts in spatial information, as well. The value of these concepts is growing, and researchers more and more discuss additional outcomes, such as 'promotion of new research through existing data', 'verification-refutation or refinement of original results', 'better data quality' and 'greater accountability' [3,4].

In the above-mentioned context, research has been done regarding systems that manage measurement data in the scientific field of surveying engineering. Buyond et al. [5] analyzed the concept of measurement-based cadastral systems, and Goodchild [6] discussed the differences between coordinate-based and measurement-based GIS. Navratil et al. [7] worked on an ESRI ArcGIS product test case, in the generic frame of measurement-based GIS, and Leung et al. [8] proposed a general framework for error analysis in measurement-based geographical information systems (MBGIS). 
Although there is yet no widely-accepted implementation developed, researchers put effort in defining and creating the necessary building blocks of measurement-driven systems.

The above concept implementation in land surveying is yet another promising field of research. Measurements collected for this purpose (angles, distances, coordinates) would provide, if shared effectively, benefits regarding aspects of working procedures [9], such as:

- more efficient preparation for subsequent land surveys

- faster data processing

- the exchange of land survey data between different parties

- resolving of land disputes, etc.

In order to provide sharing services among users and different systems, it is important to focus on standardizing geodetic measurements' representation and also methods to access modeled information. For this purpose, the Open Geospatial Consortium (OGC) has developed a number of standards to meet the above requirement. In the context of Sensor Web Enablement (SWE), OGC has developed the ISO 19156:2011 standards on Observations and Measurements (O\&M) that describes a framework and encoding for measurements and observations. The O\&M standard has been widely used and implemented in other representation packages as parts or extensions. The Land Administration Domain Model (LADM [10,11]; previously called the core cadastral domain model), has been designed by the International Federation of Surveyors ('Fédération Internationale des Géomètres'-FIG) in order to model land administration information. Its last edition became an international standard (ISO 19152:2012) that itself integrates, among others, the 'OM_Observation' definition from the ISO 19156:2011. Furthermore, information policy makers officially require the establishment of sharing components in infrastructure for spatial information. In the EU, for example, the INSPIRE directive [12] has issued specific implementation guidelines regarding the O\&M standard [13] that partially extend the model.

In regard to the requirement for services that provide system interoperability, OGC has developed the Sensor Observation Service (SOS) standard. The SOS standard defines web services to search, filter and retrieve observational data and sensor information $[14,15]$. Research in the land surveying domain, regarding both measurement models and interoperability services, reveals very promising results and constantly increasing interest. Oosterom et al. [16] discussed among other issues the spatial unit (LADM), 'LA_Source' (LADM) and 'OM_Observation' class (ISO 19156). Kandawasvika [17] discussed a general framework implementing OGC standards for geodetic sensors in the context of landsite monitoring. Finally, Vranic et al. [9] worked on land surveying data and developed a model for GNSS measurement systems, based on the 'OM_Observation' standard.

The development of a land surveying observation model is an essential prerequisite in order to enable efficient observation sharing and service deployment among users. The key motivation derives from the raw observation repository development and especially the option to save, query and retrieve multiple observations that refer to the same observed quantity. The consideration of such an approach provides major benefits over multiple aspects, namely:

- The availability of data provided over different operating conditions (operator, equipment, environmental parameters) for the same measured quantity is necessary in order to determine the best approximation of the true value of a measured quantity.

- Land surveying field observations require considerable resources (field time, equipment, and operators); thus, the raw measurements dataset is an expensive product to collect just to use only once.

- The lack of land surveying field observation standardization makes data exchanging difficult as different equipment manufacturers use different file structures.

- Access to modeled observation repository enables land surveyors to cross-validate their data with past available measurements and ensure product compatibility to the wider area of interest. 
- Access to existent data can provide better quality or reduce the cost (or both) of the land surveying final product.

In this paper, the conception and implementation of an OGC O\&M standard-compliant, land surveying measurement model are described. This work has originated within the Collaborative Cloud Land Survey (CCLC) [18] research context as a backbone system layer of the introduced architecture. Section 2 presents the core of the O\&M encoding, but also discusses the OGC Sensor Observation Service (SOS) and Sensor Modeling Language (SensorML). Section 3 analyzes the proposed implementation of the O\&M standard in the domain of land surveying terrestrial observations, focusing in Total Station/Positioning Systems (TPS). Section 4 discusses a case study where an SOS web service is utilized, XML request documents are developed and Web Map Service (WMS) visualization modes are demonstrated in order to explore application requirements, restrictions and potential benefits.

\section{OGC-Sensor Web Enablement Initiative}

The Open Geospatial Consortium (OGC) is an international not-for-profit organization committed to making quality open standards for the global geospatial community. These standards are made through a consensus process and are freely available for anyone to use to improve sharing of the world's geospatial data [19]. The organization preexisted as the Geographic Resources Analysis Support System (GRASS) Foundation from 1992. In 1994, GRASS was renamed to the Open GIS Consortium, and since 2004, it is officially known as the Open Geospatial Consortium (OGC) [20]. Currently, OGC has over 500 members (Companies, universities, non-profit organizations, government agencies, research organizations) that contribute to the development of publicly available standards [21].

OGC standards are technical documents that detail interfaces or encodings. These documents, known as abstract specifications, define the common information protocol guidelines, applied by developers in order to create open interfaces and encodings to their product and services. Currently (September 2016), over 40 standards have been developed that constitute the base of interoperability development in the spatial information and services domain. 'Geography Markup Language' (GML), 'Keyhole Markup Language' (KML), WMS and 'Web Feature Service' (WFS) are recognized standards in every web-enabled, commercial or open-source GIS implementation, as their utilization provides major operational advantages over other arbitrary solutions regarding systems interoperability.

\subsection{Sensor Web Enablement}

In order to enable developers to make sensors and sensor data repositories discoverable, accessible and useable via the web, OGC has specified interoperability interfaces and metadata encodings facilitating the integration of heterogeneous sensor webs into the information infrastructure [22]. Sensor Web Enablement (SWE) standards have been developed by OGC to define the specifications for creating applications, platforms and products involving web-connected devices. Each of the following OGC standards has been developed to address different requirements of the SWE framework initiative.

- Observations and Measurements (O\&M) defines models and XML schema for encoding sensor observations and measurements (Section 2.2).

- The Sensor Model Language (SensorML) (currently v2.0) provides the framework to describe the characteristics and capabilities of sensors and systems, associated with the measurement and post-measurement transformation. By adopting SensorML, the developer can define models and XML schemas to describe any process (sensor system measurement or post-measurement processing), though it is best suited to sensor systems and processes of sensor observations. In the context of this paper, SensorML is discussed as the information provider about sensor characteristics and the process of observation acquisition.

- The Sensor Observations Service (SOS) is a standard to define the web service interface for requesting, filtering and retrieving observations and sensor system information (Section 2.3). 
Furthermore, SWE also consists of the Transducer Model Language (TML), Sensor Planning Service (SPS), Sensor Alert Service (SAS) and Web Notification Services (WNS) standards [23] that refer to concepts and functions that will not be discussed in the context of this paper.

\subsection{ISO 19156:2011: Observations and Measurements Standard}

The OGC Observation and Measurement standard, published as ISO 19156:2011, originated in the work of OGC's Sensor Web Enablement (SWE) activity, as previously discussed. In the context of SWE, the O\&M standard defines models and XML schema for encoding sensor observations and measurements.

'Measurement' has been defined as the process of 'experimentally obtaining one or more quantity values that can reasonably be attributed to a quantity' [24]. Observation is the 'act of observing a property, having goal of an observation may be to measure or otherwise determine the value of a property' (ISO/DIS 19156:2010). Both of these closely-related concepts incorporate the action (process), the subject (feature of interest), the property to measure and the result of the process. This abstract approach has been adopted by the O\&M standard definition so that the final model can be applicable across a wide variety of application domains. The O\&M standard [25] defines as key properties of an observation the 'featureOfInterest', the 'observedProperty', the 'procedure' and the 'result'.

The 'procedure' element, referenced as the 'OM_Process' class, defines the description of a process used to generate the observation result. An instance of 'OM_Process' is often an instrument or sensor, but may be a human observer, a simulator or a process or algorithm applied to more primitive results used as inputs [26]. As defined in the context of the O\&M standard, it is abstract; it has no attributes, operations or associations and must be extended in order to become suitable for the observed property.

The 'featureOfInterest' is a feature of any type (ISO 19109, ISO 19101) [27,28], which is a representation of the real-world object, regarding which the observation is made. The phenomenon that is observed by the model is referenced by the 'observedProperty' element, and it can be a single scalar value or a composite multi-component phenomenon descriptor. Finally, the 'result' element contains the value generated by the procedure. The type of observation result must be consistent with the observed property, and the scale or scope for the value must be consistent with the quantity or category type. Figure 1 (created based on the OGC Observation and Measurement standard [25]) illustrates the core class diagram of the O\&M conceptual model that is aligned to the above classification schema.

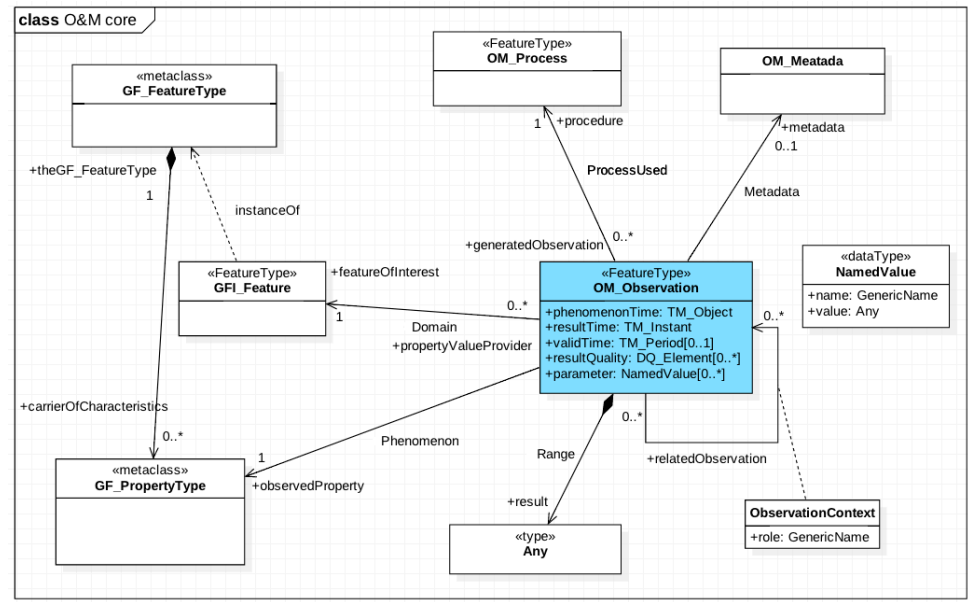

Figure 1. Core class diagram of Observations and Measurements (O\&M) conceptual model.

\subsection{Sensor Observation Service}

OGC defines Sensor Observation Service (SOS) (this paper refers to SOS 2.0 specifications) as a standard that 'provides an API for managing deployed sensors and retrieving sensor data and 
specifically "observation" data' [15]. The goal of SOS is to provide access to observations from sensors and sensor systems in a standard way that is consistent for all sensor systems. In order to be consistent with its definition, SOS specifies a set of operations that can be used to request available data (operations for the sensor data consumer) or to publish information (operations for the sensor data publisher). These are classified into the core operations and three extensions.

The SOS 'Core' requirements class defines three operations for retrieving data from the repository. 'GetCapabilities' allows clients to access the service metadata of a specific service instance. 'DescribeSensor' is designed to request detailed sensor descriptive information. Usually, the Sensor Model Language (SensorML) or the Transducer Markup Language (TML, which has been rarely used, and the retirement of the standard is under discussion [29]) is used to encode the response to this request. Finally, the 'GetObservation' operation retrieves observation data structured according to the observation and measurement specification, filtered by spatial, temporal and thematic properties. The above three operations of the core profile of the SOS are mandatory and have to be offered by every SOS implementation.

The 'transactional extension' refers to three operations that allow the user to register new data and sensors into the SOS and also inserting new observations. The 'InsertSensor' request sends a SensorML description of the sensor to be added. The response returns the assigned sensor id that can be used as a parameter of the 'InsertObservation' operation to add new observations. The 'DeleteSensor' operation allows the deletion of registered sensors and all of their associated observations. The above operations are defined as optionally implemented into SOS systems.

\subsection{Implementations-Extensions}

O\&M standards have been implemented as needed in a wide range of projects, standards and guidelines that refer to modeling of the observation procedure [30-32]. This paper examines concepts in the frame of land surveying information management and implementation; thus, three cases relevant to the surveying engineering context shall be mentioned, namely the INSPIRE Guidelines for O\&M and SWE use, the FIG Land Administration Standardization with a focus on surveying and spatial representations and the Vranic et al. O\&M GNSS implementation.

The European Commission established the Infrastructure for Spatial Information in the European Union (INSPIRE) frame, requesting that data should be collected once and reused. In the context of this initiative, a special document that refers to observation and measurements and sensor web enablement standards has been developed. Due to the fact that the O\&M standard provides a generic framework for the provision of measurement data, there are many ways of utilizing the core structures. The provided guidelines ensure compatibility across INSPIRE applications, thus should be taken in to account in all INSPIRE themes integrating or referencing to the O\&M standard [13]. The developed document discusses fundamental concepts of the O\&M standard along with case-specific application paradigms.

The International Federation of Surveyors (FIG) has developed the Land Administration Domain Model. Primarily, it was named as the 'Core Cadastral Domain Model', and finally, it evolved into ISO 19152:2012 Geographic Information-Land Administration Domain Model (LADM) [10]. The main objective of this work was to define a conceptual model related to parties, ownership rights, spatial units, spatial sources (surveying) and spatial representations (geometry and topology). The modeling of spatial sources is made by developing the described 'LA_SpatialSource' class that represents an integral part of the land administration system. The definition of the above class implements the OM_Observation and OM_Process of O\&M standard, indicating this way the strong conceptual relation between land surveying measurement data and discussed concepts. Van Oosterom et al. [16] discussed further the use of the above model in the context of land administration and provided land surveying measurement level examples.

Finally, Vranic et al. [9] discussed the use of the O\&M OGC model in the context of land surveying. More specifically, an implementation of the standard was introduced, and a model for GNSS measurements was developed. This work discussed the use of the model in the context of the 
Croatian Surveying Community, providing the use concepts and benefits of O\&M implementation on land surveying data. Figure 2 shows the developed GNSS model.

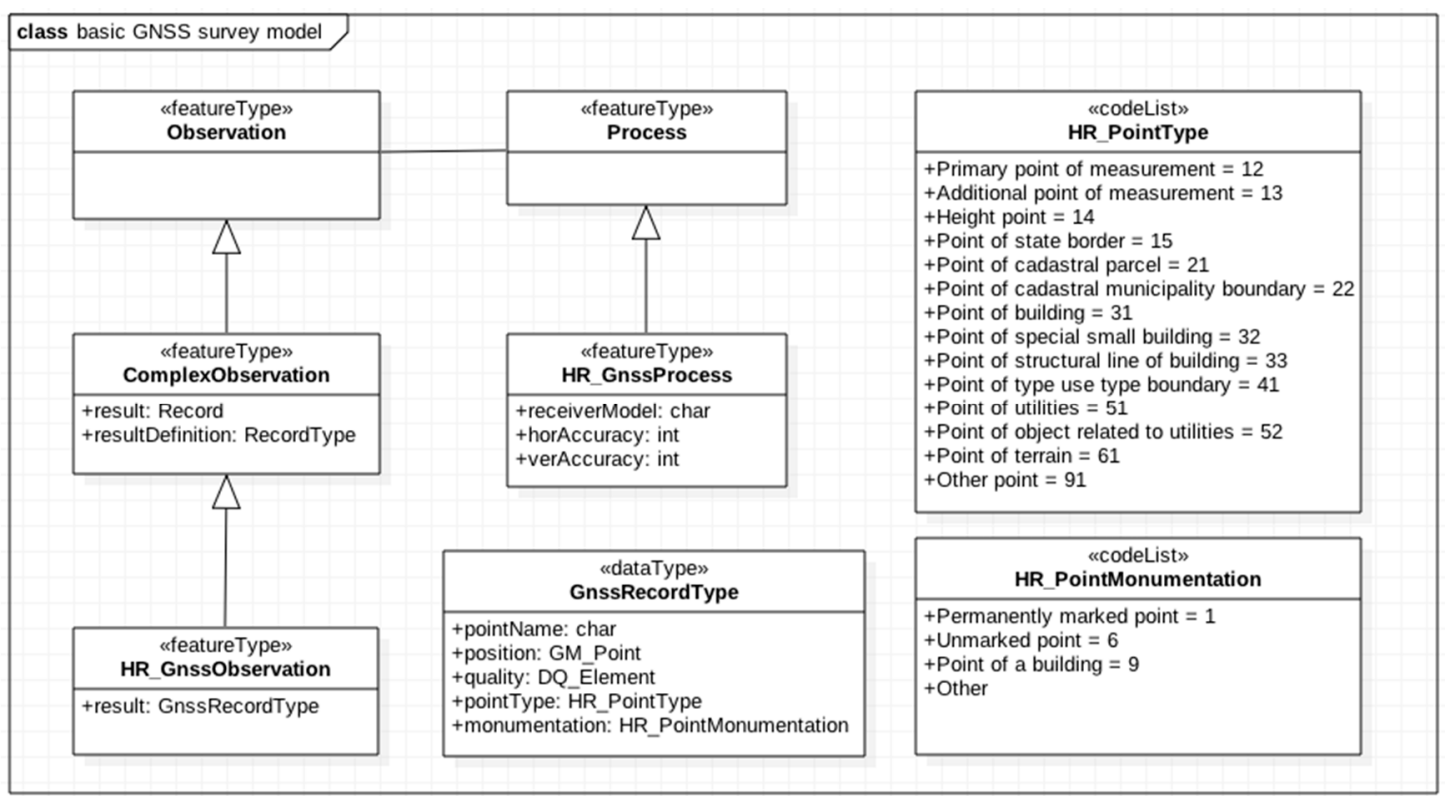

Figure 2. Core class diagram of the 'HR_GNSS' O\&M conceptual model.

The above approach considers the point of measure to be the feature of interest, while the process is described by the specification and the model of the receiver. The result is a set of information that contains the name, position, measurement quality, point type and point monumentation.

\section{Definition of Model}

Based on the reviewed literature and relevant work, a model that refers to land surveying measurements will be discussed, and the corresponding classes that define the model will be developed. By using the OGC O\&M conceptual model, land survey observations can be modeled and be used as a source for measurement-driven data management systems, analysis tools that benefit from raw data and global observation exchange platforms. The following analysis is structured according to the fundamental "feature of interest-observed property-process-result" discussion pattern.

\subsection{Feature of Interest}

The first consideration to be made in the process of creating a model that refers to land surveying measurements is to clearly define the 'feature of interest' concept. According to ISO 19109, it should be a representation of the observation target, being the real-world object regarding which the observation is made. The land surveying measurement process is about obtaining data describing the relation between two points in space. The first one acts as an observation base and the other as the remote object. While it is easy to understand that the feature of interest is not the base point, it should be remarked that neither is the remote object. Total stations and GNSS equipment are used to measure quantities, such as:

- Slope distance from the set point to the remote target

- Horizontal direction from the set point to the remote target

- Vertical angle from the set point to the remote target

- Time or carrier phase that refers to the signal received from the set base and transmitted from the space vehicle. 
The above considerations make it clear that this kind of observation refers to a three-dimensional vector. In the context of this paper, the model's feature of interest is the physical instance of base-target vector representation, called the observable vector (Figure 3).

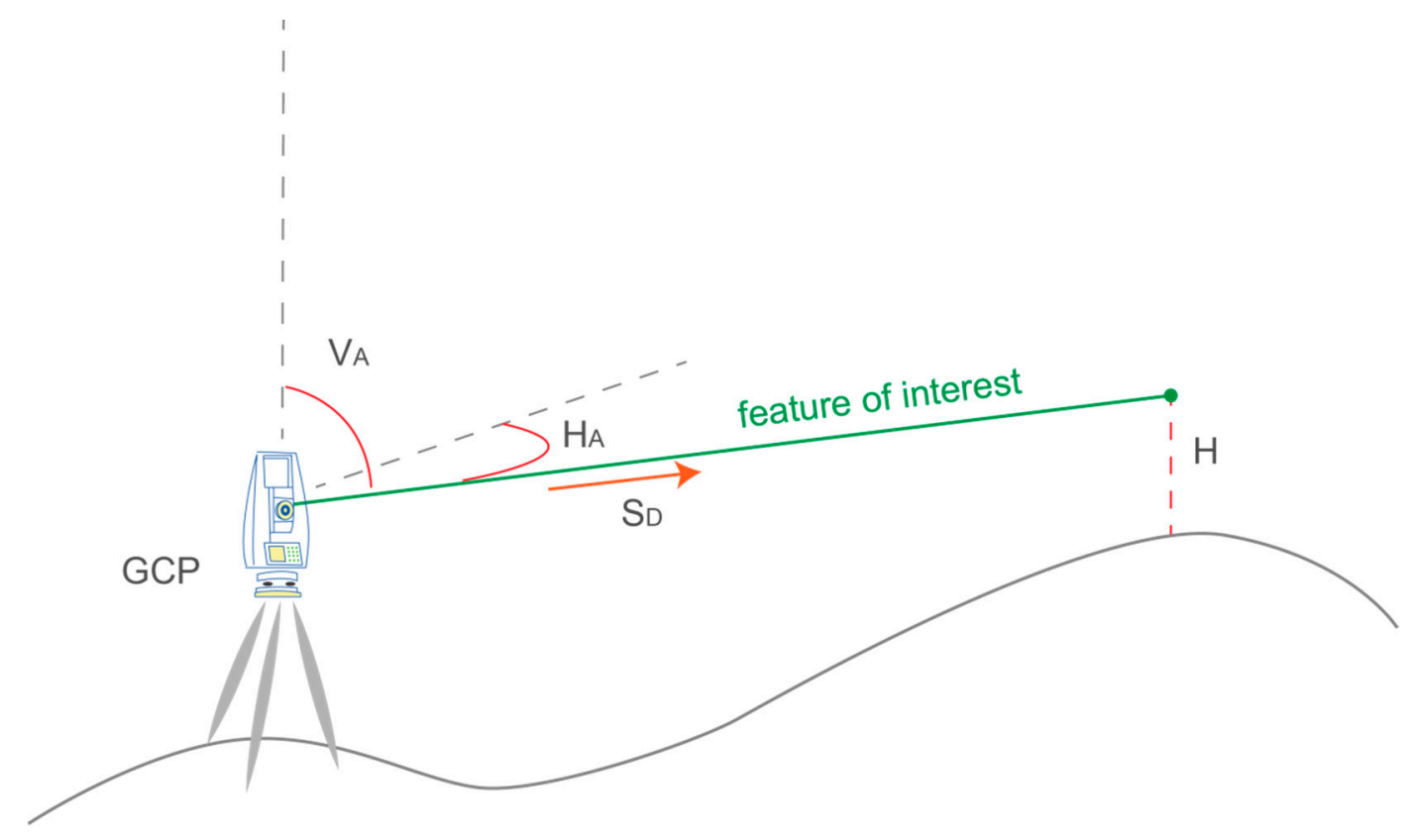

Figure 3. Observable quantities of the feature of interest.

\subsection{Process}

After defining the feature of interest, it is necessary to describe the observation acquisition procedure. In order to determine the structure of the 'process' class, it is required to identify the attributes that uniquely define the model. In land surveying, the measurement acquisition procedure is strongly related to the equipment initialization. Whenever a total station is set over a base point, there are specific parameters that are set and fixed, which remain unchanged until the next base point setup. This information not only is required during the data processing, but also contains metadata that allow the evaluation of the collected measurements, the final result and the process itself. More specifically, in the context of this paper, the following attributes are addressed to describe the 'process' class.

The equipment used is an object to be described. Information that refers to accuracy is required in order to evaluate collected observations or compare different sets of measurements. The identification structure of the total station consists of the manufacturer, the instrument model and the date of the last calibration. Furthermore, the accuracy specifications are required regarding all types of measurement available, which are angular observation accuracy (separately horizontal and vertical if available) and distance observation accuracy.

As mentioned above, every measurement process starts with the initialization of the total station over an established control point. Data that refer to the base setup are required for the computation procedure and should be implemented in the definition of the model. This consists of information regarding the identification of the control point that is a description attribute, filed notes and type of monumentation. Additionally, the equipment setup height, over the control point, provides necessary information in order to extract the third dimension (height) for all of our observed points.

Finally, data referring to the operator can provide information to estimate or evaluate measurement quality. Furthermore, the operator-equipment system can provide, given further statistical analysis, the detection of systematic error patterns, thus increasing the accuracy of estimated 
quantities. Based on the latter, contact information, experience in land surveying and field of expertise are integrated into the developed model.

\subsection{Observed Property Result}

As stated above, each measurement provides one or more quantity values that refer to the geometric instance of the observable vector. These can be the distance between the set point and the remote target, the horizontal direction that refers to a random, but fixed for each measurement set, origin or the vertical angle defined as the angle defined by the zenith and observable vector. The above are the core observation data that a surveyor engineer collects in the field.

Nevertheless, these values are to be provided with other information that is required to define the vector, but also relevant observation metadata. The height of the remote target is a required attribute for extracting the third dimension from field measurements. Furthermore, descriptive information should be recorded both in non-structured (description notes) and structured (point type, observation type) attributes.

\subsection{Class Diagram}

The above discussion provides the necessary knowledge of land surveying work and data context for exploring this paper's model requirements. Based on this knowledge, an extension of the core O\&M model has been developed, which is aligned to the specific requirements of land surveying previously described. The classes of this model have been prefixed as 'LS_', standing for Land Surveying.

Figure 4 shows the 'LS_Process' class that is an extension of the 'OM_Process' class of the O\&M OGC standard. Each of the previously discussed attributes is implemented so that the 'LS_Process' object can effectively describe the actual land surveying process. Additionally, Figure 5 depicts the 'LS_Observation' class deriving from the 'OM_Complex_Observation' class. LS_Operator, LS_TotalStation, LS_Accuracy and LS_Point are introduced to define and integrate into the model the above discussed entities of operator, total station, accuracy and ground point instance. Multiple measurements (angles, distances) are modeled through 'OM_ComplexObservation', where record type indicates the type of measurement.

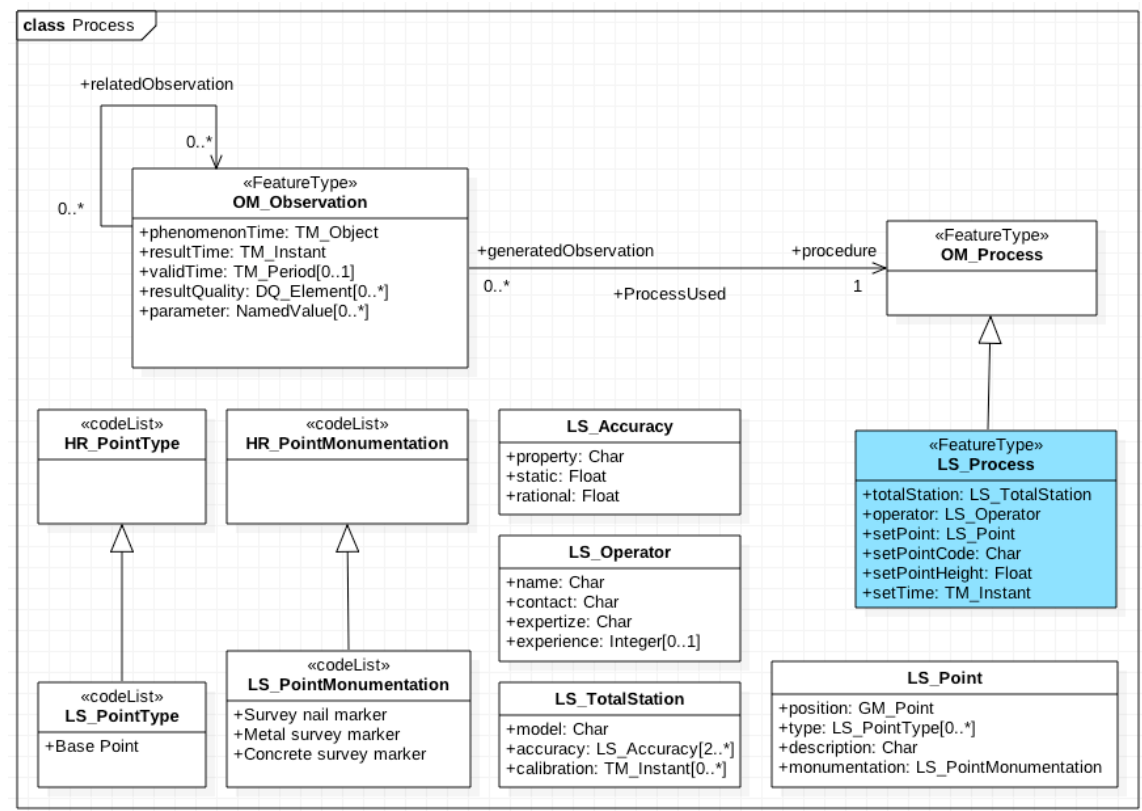

Figure 4. 'LS_Process' core class diagram. 


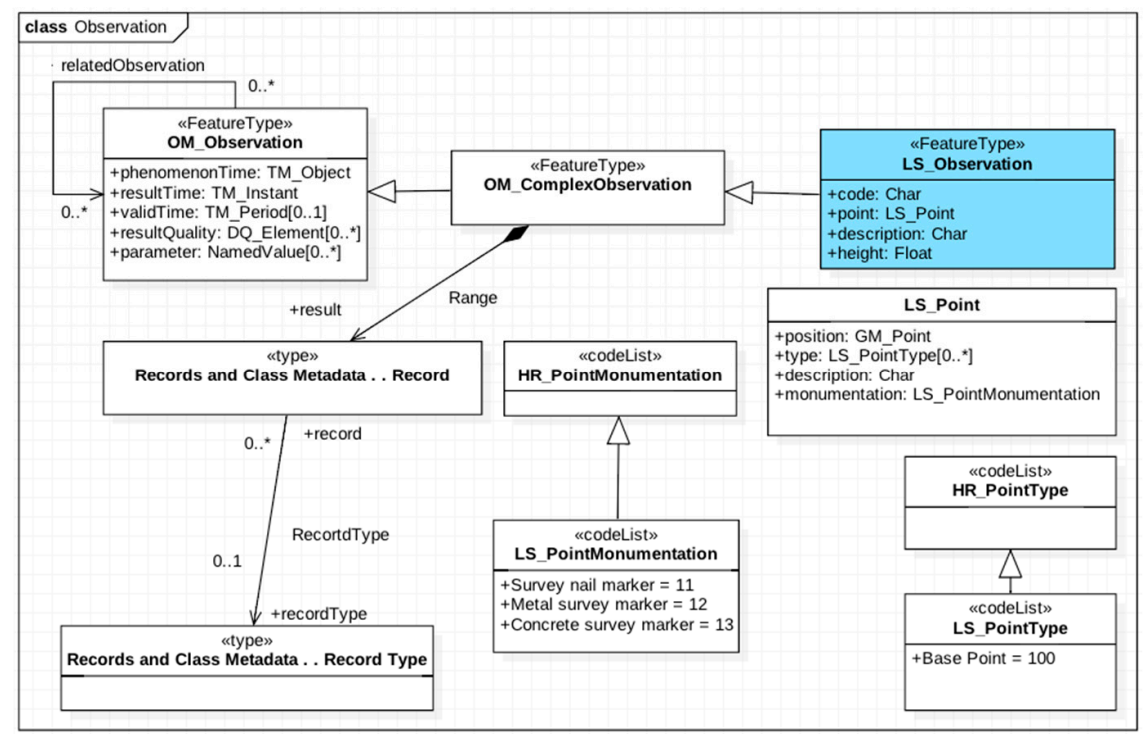

Figure 5. 'LS_Observation' core class diagram.

\section{Sensor Observation Service: Observation Visualization}

Analysis regarding the efficiency and potential benefits emerging from adopting the O\&M standard modeling approach requires the implementation of a web interoperable service. Furthermore, a measurement repository along with a web service that will grant access to stored measurements can provide the basis for future research on data-driven information analysis concepts, in the domain of land surveying, like unsupervised network analysis or 'equipment-operator-environment' evaluation algorithms. The Sensor Observation Service (SOS) standard that has been defined by OGC provides the specifications for the required operations and has been implemented by various programming languages and application frameworks [33]. It should be noted that considerations regarding performance issues emerge when handling mass spatio-temporal data; thus, research interest regarding the use of cutting edge technologies is under discussion (e.g., applications based on NoSQL, MongoDB or the SQL Cloudera Impala engine [34,35]).

In the context of this paper, the $52^{\circ}$ North SOS software has been adopted as the implementation framework since it is widely used, open-source and consistently updated. The server environment is set on the Linux Ubuntu 14.04 OS distribution with JRE7 and tomcat installed. The data are stored in a relational database management system (RDBMS) PostgreSQL 9.1 with the PostGIS 2.1 extension installed.

The $52^{\circ}$ North SOS management module is built as a web application that provides administrative management functions though a simple, yet effective, to use interface. It supports core, enhanced, transactional and result handling extensions. The described case study has implemented the three operations of the core profile (GetCapabilities, GetObservation, DescribeSensor) so that users can query the system for available sensors and observations. Additionally, the operations 'InsertSensor' and 'InsertObservation' of the transactional extension have been used to feed the database with available information.

The test dataset consists of 41,515 TPS observations, which have been collected in the field (10,379 features of interest) in a high density urban area. The reference network consists of 210 Ground Control Points (GCP) over which 228 observation processes have been initialized, as some GCP have been used more than once. Out of the 41,515 (10,379 features of interest) observations, 3678 (1226 features of interest) refer to GCP and define the sub-dataset that is processed to define the geometry of the reference network. The observation process provides one to four observations for each feature of interest (horizontal angle, vertical angle, slope distance, target height, as illustrated in Figure 3). Figure 6 shows part of the GCP (yellow pin) distribution over the satellite image, and Figure 7 depicts the corresponding reference network (purple lines). 


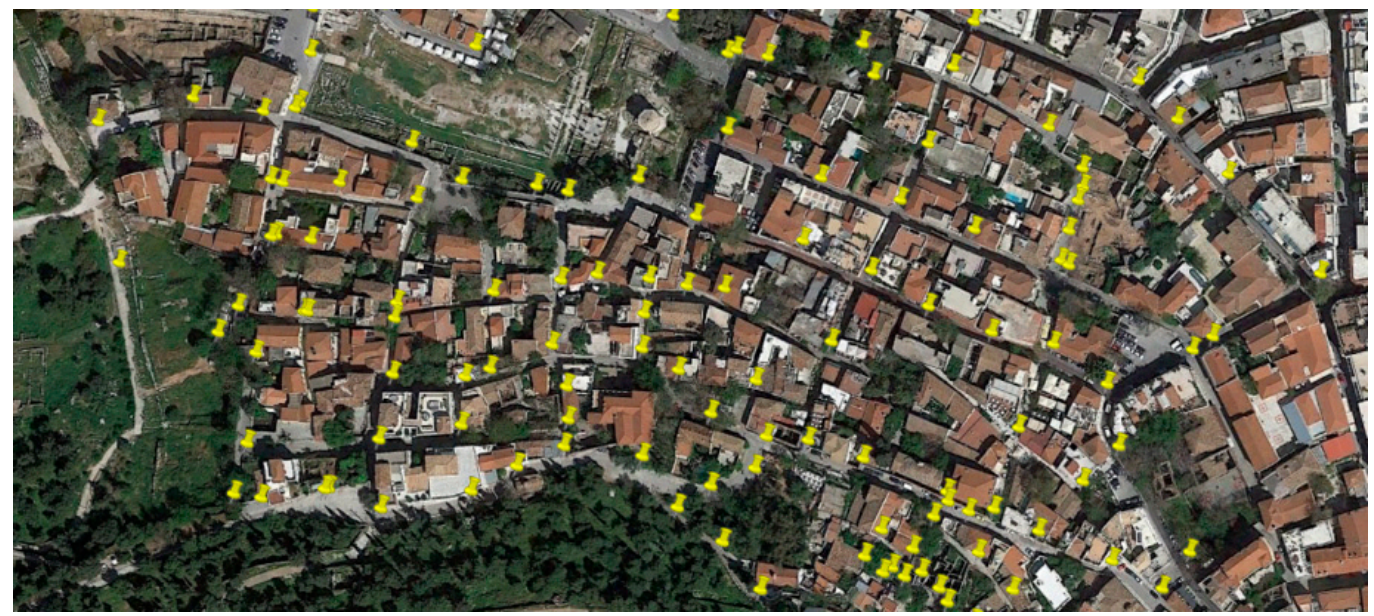

Figure 6. Ground Control Point (GCP) distribution.

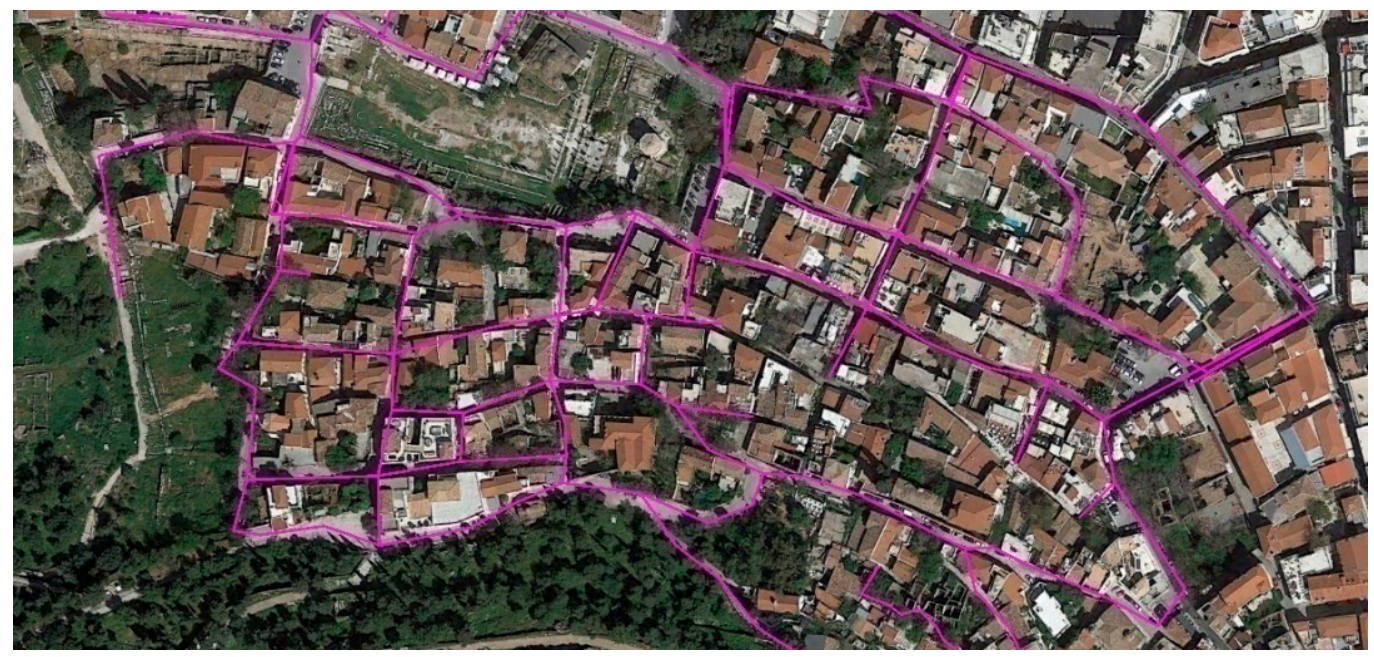

Figure 7. Reference network for available GCPs.

This case study aims at exploring the use and the requirements of the sensor observation service implementation. Under this consideration, a direct feed of the PostgreSQL databases is not the approach to be followed. Instead, appropriate XML (POST) requests have been developed so that all available data can be entered by utilizing SOS transactional 'InsertSensor' and 'InserObservation' operations. The above-mentioned XML requests have been developed considering both the requirements of described land surveying O\&M model (Section 2) and the specific characteristics of the selected implementation system.

\subsection{Insert Sensor}

The proposed model considers the TPS equipment as a sensor device that instantiates a corresponding process every time a measurement procedure is initialized. The insert sensor operation is the SOS-provided web-based interface for publishing sensor systems (processes in the context of O\&M standard) to the developed repository. $52^{\circ}$ North SOS supports the SOS2.0 version, while the published sensors are described according to SensorML2.0 ("Sensor Markup Language" (SML) namespace) specifications. The XML document that structures the corresponding information consists, among other data, of three important building blocks that refer to the process-sensor entity. The first encapsulates information that describes and identifies the process itself. Figure 8 shows the XML part that provides unique id information, description fields and setup parameters. The second building 
block (Figure 9) is used to define the output of the process (type of measurements, units, etc.), and the third one (Figure 10) provides information about the position of the sensor.

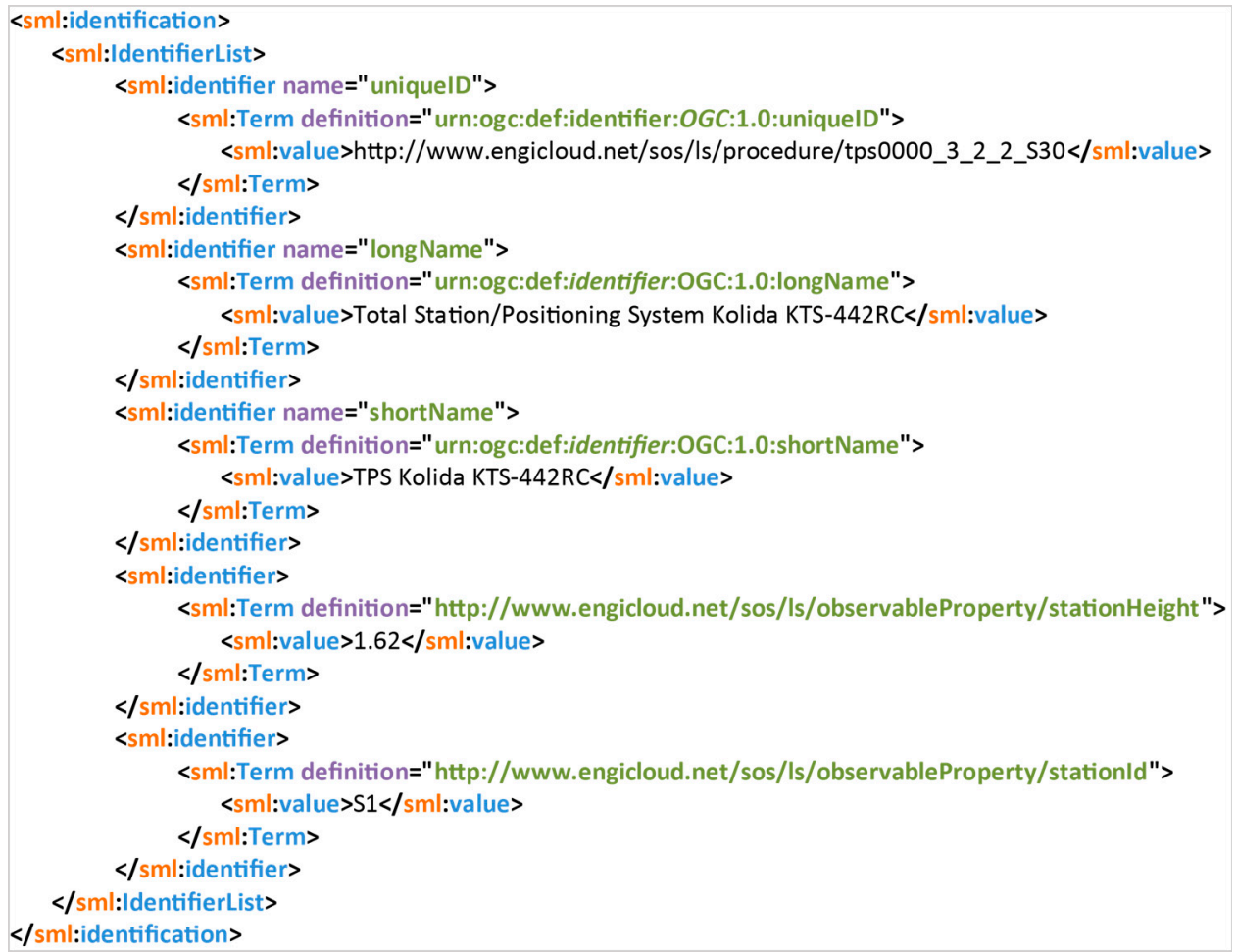

Figure 8. Insert sensor XML request, identification property (SOS-SML2.0).

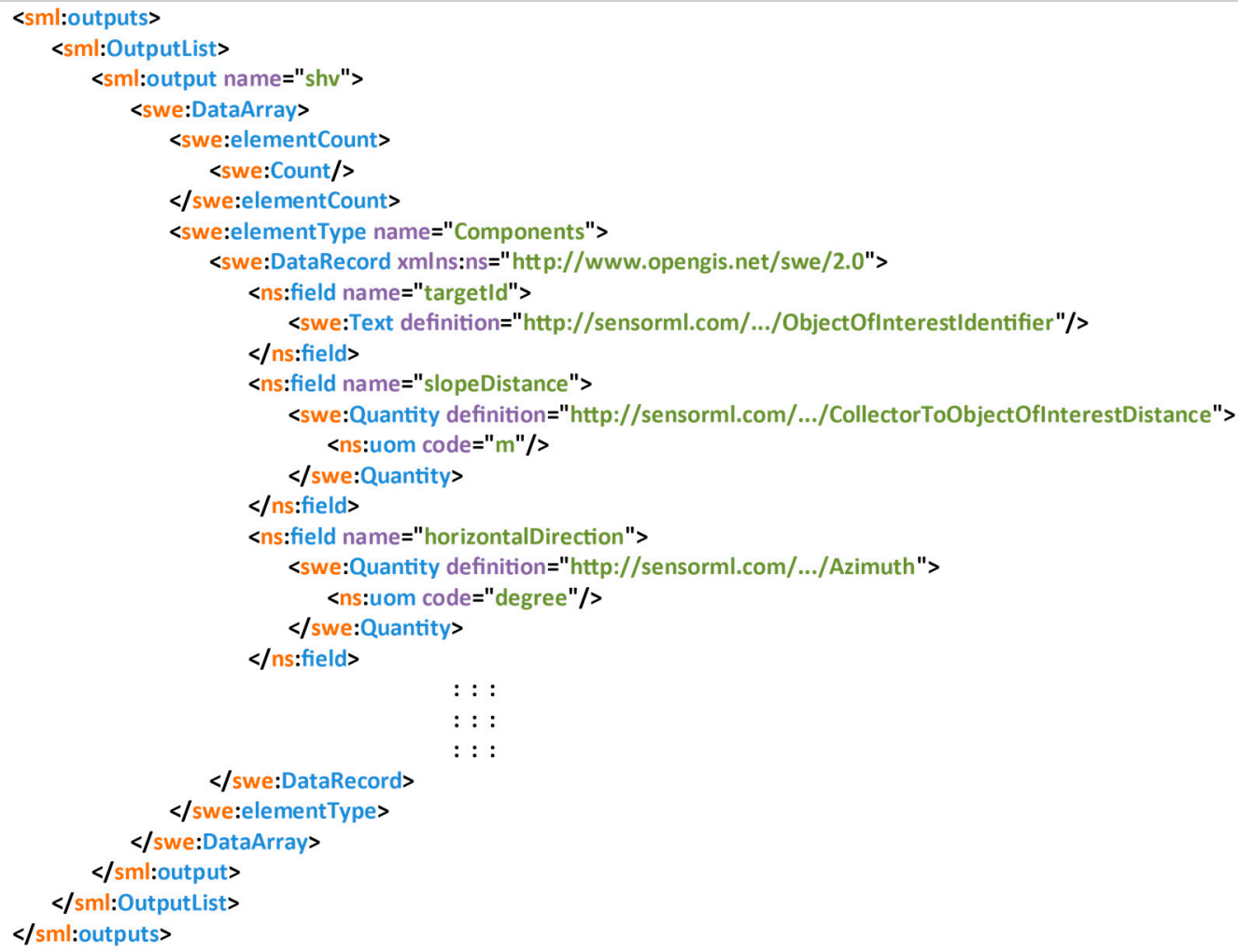

Figure 9. Insert sensor XML request, output property (SOS-SensorML2.0). 


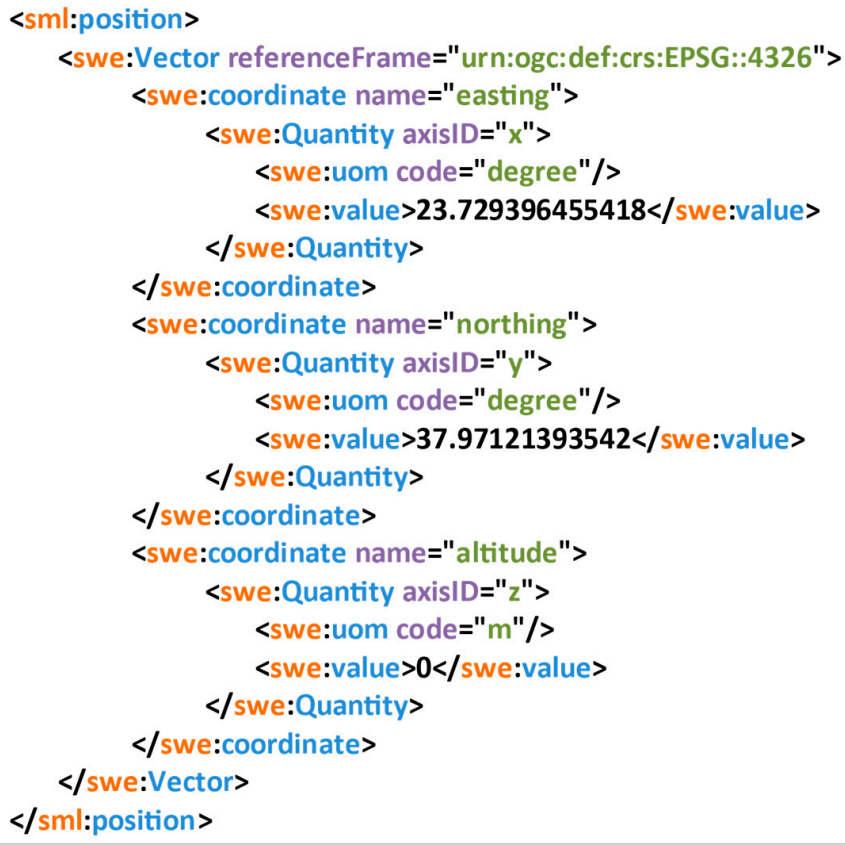

Figure 10. Insert sensor XML request, position property (SOS-SensorML2.0).

\subsection{Insert Observation}

'Insert observation' is the required operation, along with 'insert sensor' that is used to feed the repository and is also part of the transactional SOS operations. The $52^{\circ}$ North SOS implementation supports this operation, provided that the appropriate POST requests are aligned to the previously discussed sensor definition. Figure 11 shows an XML example (excluding the XML namespaces) of a complex observation insertion to the repository that consists of a horizontal angle ("azimuth"), a vertical angle ("AlphaAngle"), a slope distance ("CollectorToObjectOfInterestDistance") and the target height ("HeightAboveGround"), all referring to the same feature of interest. In the first observed property, "phenomenonTime" and "featureOfInterest" are declared so that they are not repeated in all four observed properties.

\subsection{Visualization}

The above discussed repository contains several thousand observations that should be visualized over other spatial information datasets and base maps. Usually, observations come with a known position a priori and provide the measurement properties of the point of interest. This paper discusses a totally different case that introduces several challenges and problems that should be managed. The two emerging concerns come from the fact that:

- Collected observations refer to geometry quantities that "will" be used to spatially define the network of sensors and features of interest. It is an a priori spatial agnostic, but at the same time geometric self-described network.

- Observable quantities do not describe a property of a known point, but rather a set of geometric information referring to spatially-undefined features of interest.

The above remarks impose the requirement of an additional a posteriori processing layer definition that should handle positioning ambiguities in both the sensor object and the feature of interest referred to by observations. In a so-called 'Measurement-Based GIS (MBGIS)' [6] visualization, coordinates are no longer handled as required input data, but rather as output from spatial observation collections. This approach is perfectly aligned with the present work that discusses land surveying observation models and services. 


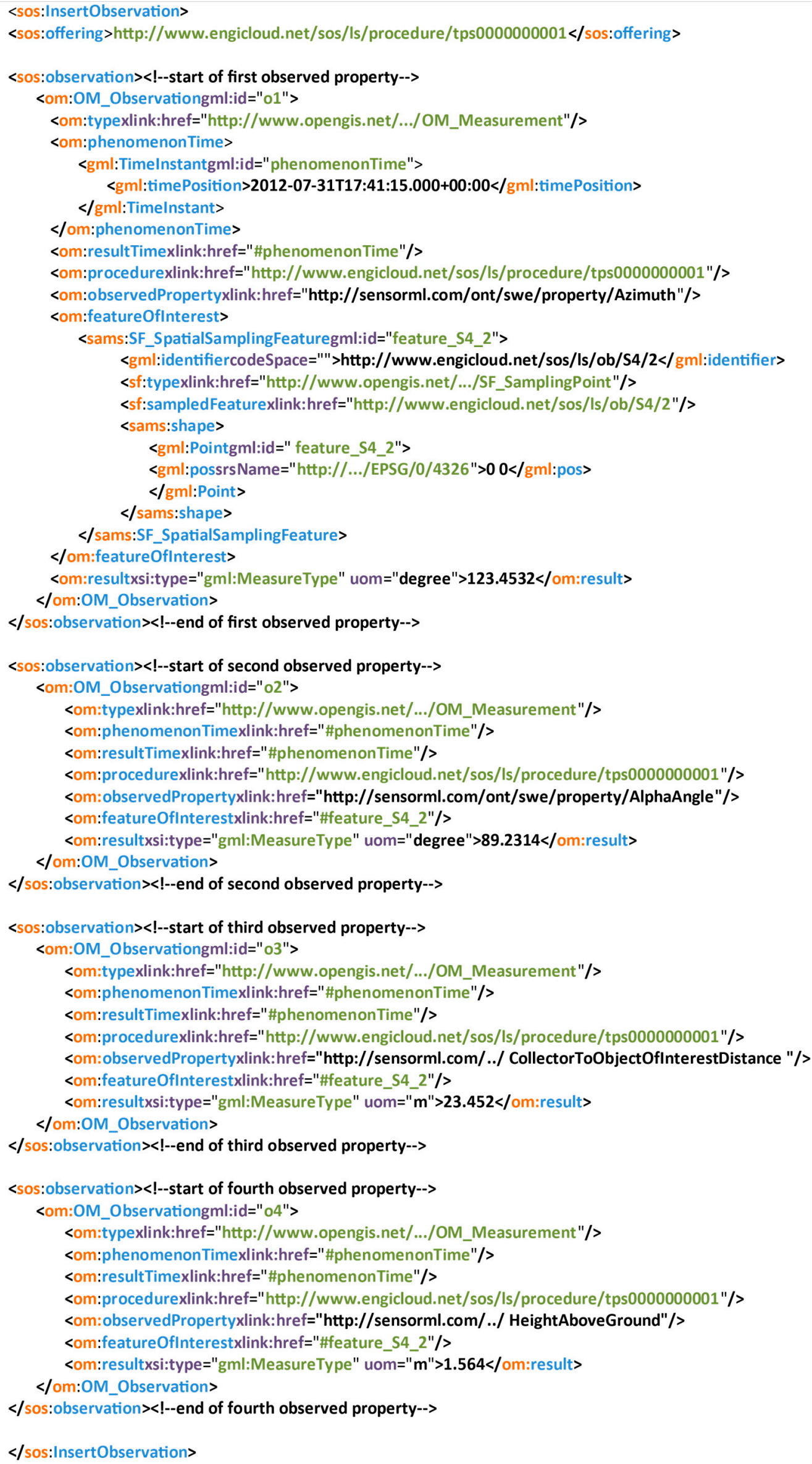

Figure 11. Insert observation XML request data. 
Considering that typical projects could contain several thousands of observations, it is easy to conclude that the fusion of multiple projects over time, space and user dimension create big data repositories [36]. Within the generic work of the 'Collaborative Cloud Land Survey (CCLC)' [18] research, unsupervised observation to coordinates transformation is achieved in real time by a developed algorithm.

By selecting two nodes of the sensor network (S0, S1), it is possible to fix the S1 position and the S1-S0 azimuth. From the latter and the fact that the observation dataset provides sensor to sensor chained measurements over the network node collection, a sequential coordinate computation procedure initiates from $\mathrm{S} 1-\mathrm{S} 2(\mathrm{Sc}=\mathrm{S} 1, \mathrm{Sb}=\mathrm{S} 2)$ and propagates through all available sensor to sensor edges. Figure 12 shows the main calculation formulas [37] used for each iteration step when $i$ is the current node, $b$ is the previous (derived from) node and $j$ the nodes to calculate.

$$
\underset{j \text { in target nodes }}{\text { for }}\left\{\begin{array}{c}
\bar{a}_{i j}=\bar{a}_{i b}+\frac{1}{n_{b, i, j}^{h}} \sum_{k=1}^{n_{b, i, j}^{d}} h_{k} \\
\bar{d}_{i j}=\frac{1}{n_{i j}^{d}+n_{j i}^{d}}\left(\sum_{k=1}^{n_{i j}^{d}} d_{i j k}+\sum_{k=1}^{n_{j i}^{d}} d_{j i k}\right) \\
x_{j}=x_{i}+\bar{d}_{i j} \times \sin \bar{a}_{i j} \\
y_{j}=y_{i}+\bar{d}_{i j} \times \cos \bar{a}_{i j}
\end{array}\right.
$$
$i$ : index of current node
$\bar{a}_{i j}:$ average azimuth angle
$b$ : index of back node
$\bar{a}_{i b}:$ known azimuth angle
$j$ : iteration index of observed nodes from $i$
$\bar{d}_{i j}$ : average horizontal distance

Figure 12. Calculation formulas.

Figures 13 and 14 illustrate the first and second step of the iteration process. Red nodes indicate known coordinates, green indicates nodes to be computed; and the underline shows the current iteration step node. Other concepts like observation declination, error statistics, network loops, etc., which are out of the scope of this paper, are also managed.

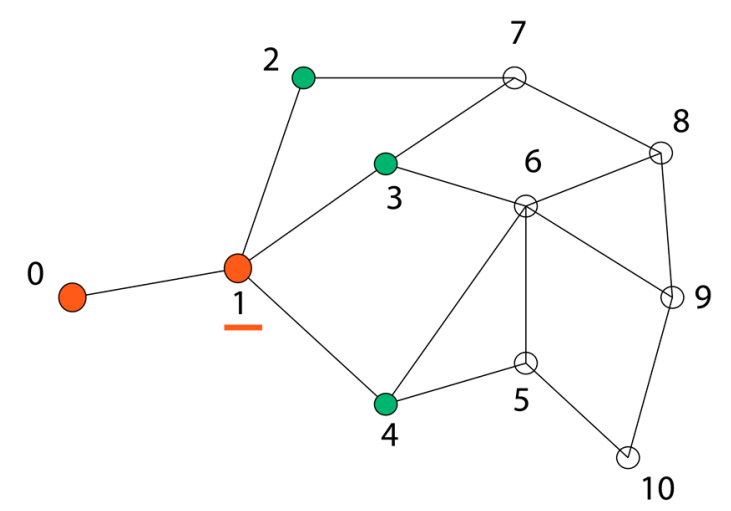

Figure 13. First step of iteration. $i=1, b=0, j \in\{2,3,4\}$. 


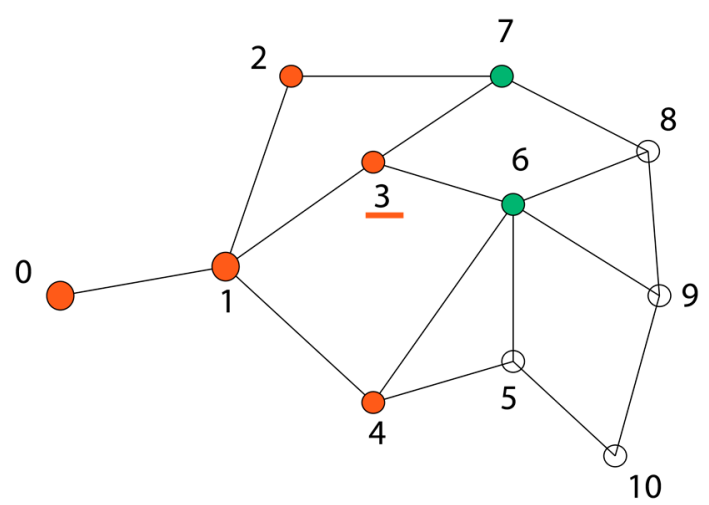

Figure 14. Second step of iteration. $i=3, b=1, j \in\{7,6\}$.

The above approach handles unsupervised network relative geometry. Given that the user provides approximate coordinates for some nodes or that the repository registry has positioning records of past processing sessions for some nodes, absolute positioning is derived for the entire sensor network. The same principle applies to the rest of the observed features (those not being part of the sensor network), so that all features of interest are spatially defined. The previously described observation post-processing layer is injected between the observation repository and the visualization layer (Figure 15).

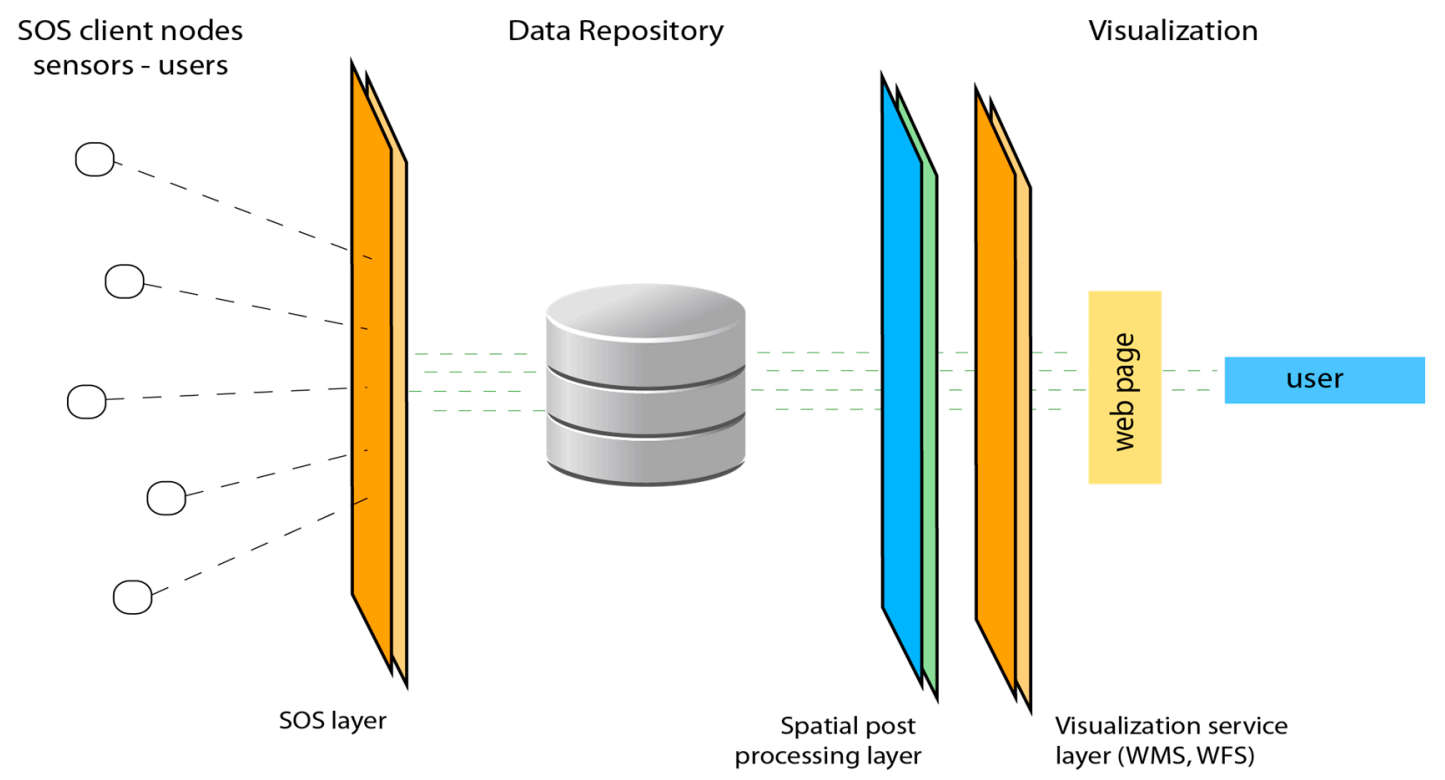

Figure 15. System architecture diagram. WMS, WFS Service layer.

The position ambiguity is reduced, and selected indexes of available observations are illustrated and overlaid on other datasets on demand. In the context of the current research, various visualization modes have been applied and demonstrated. The following figures are part of dynamic WMS service implementations that provide the rendering of available measurements by applying the appropriate queries, functions and transformations. Figure 16 shows a heat map of relative measurement density, based on the number of measurements available on each TPS base point. Even though no special data processing is used, it is possible to locate areas that lack measurements. 


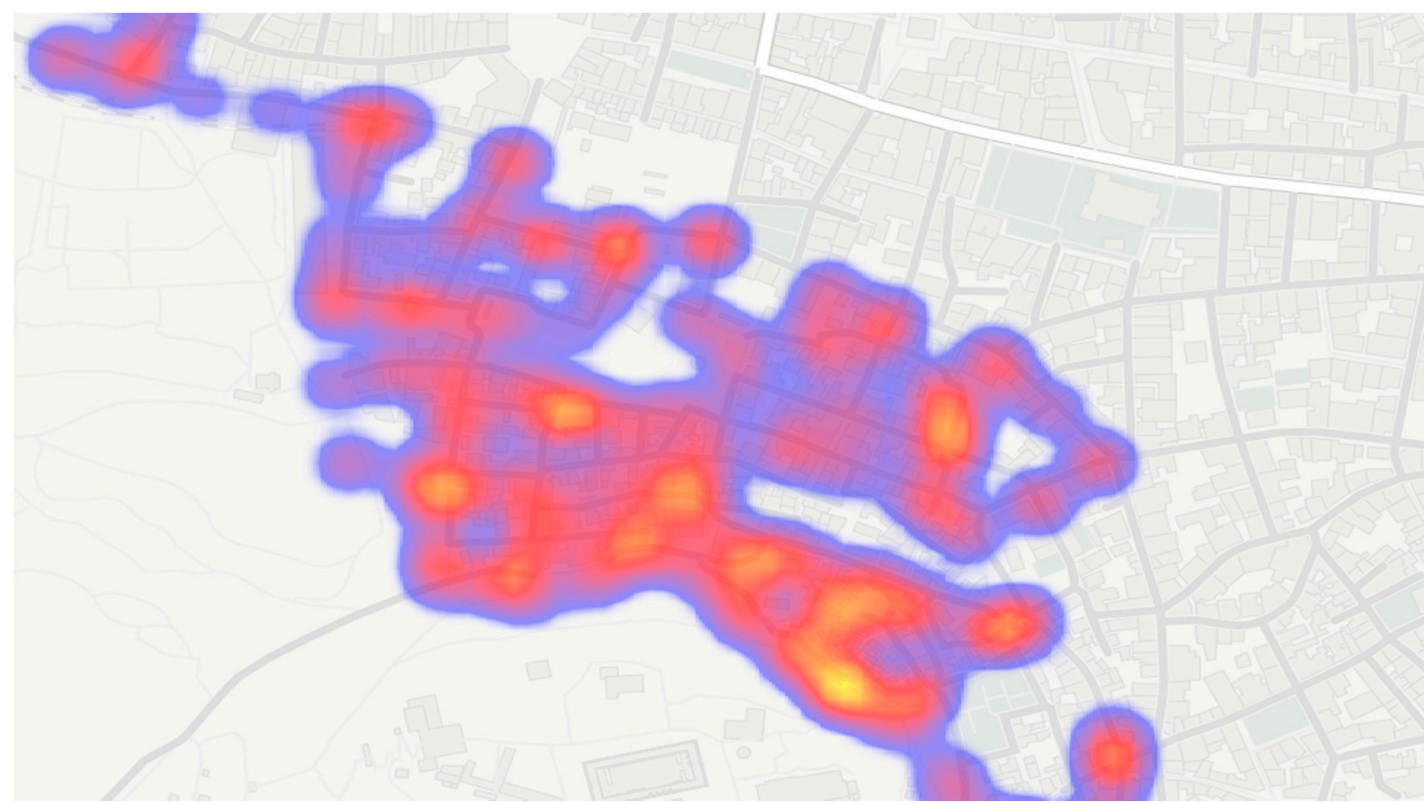

Figure 16. Heat map of relative measurement density.

Figures 17 and 18 provide a 2D illustration of the three-dimensional 'base-target' physical vector, which is the feature of interest as described in Section 3.1. Measurement processes can be identified as the converging centers of depicted lines. These are the positions of equipment (sensor) settlement. Lines of observation point to the direction of the feature of interest, while the length indicates the slope distance. All 41,515 TPS observations that have been collected in the field form the raw network of 10,379 features of interest, while coverage by different 'operator-equipment' combinations is depicted with different colors (Working Group A is indicated in blue and Working Group B in red). Erroneous observations can be directly spotted as lines that point outside of the interest area, whose distance from the base is way out of the usual range.

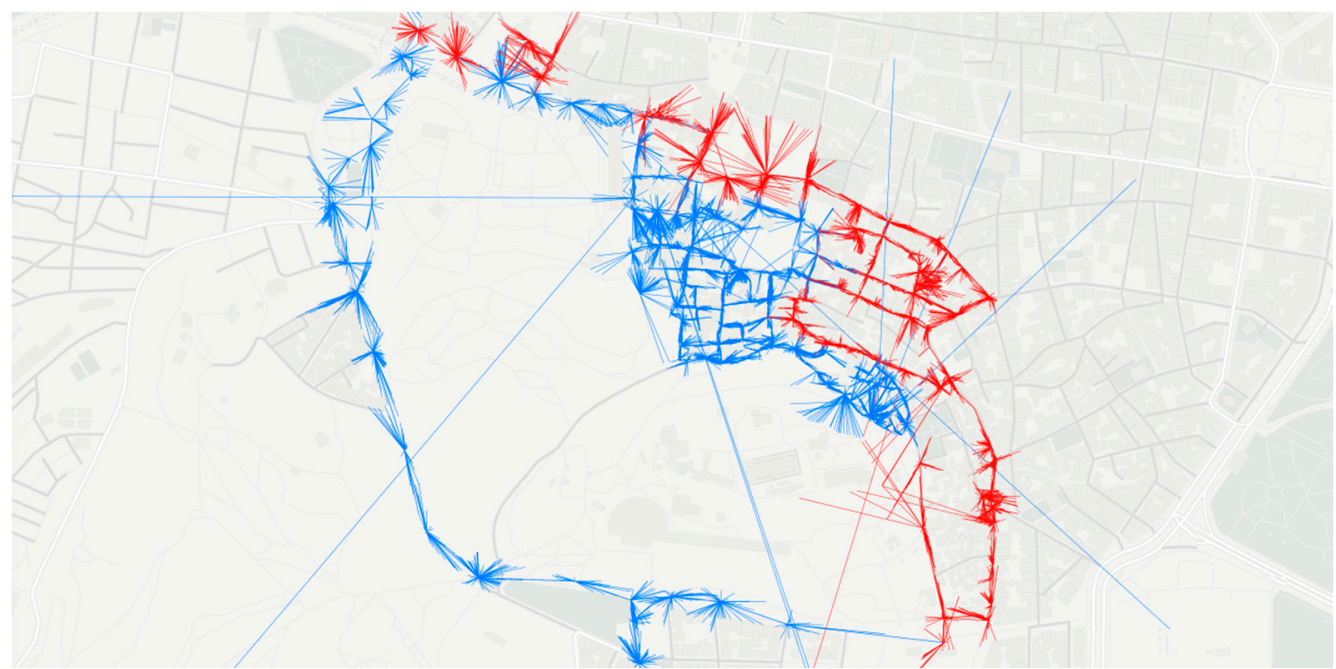

Figure 17. Network of observed features. 


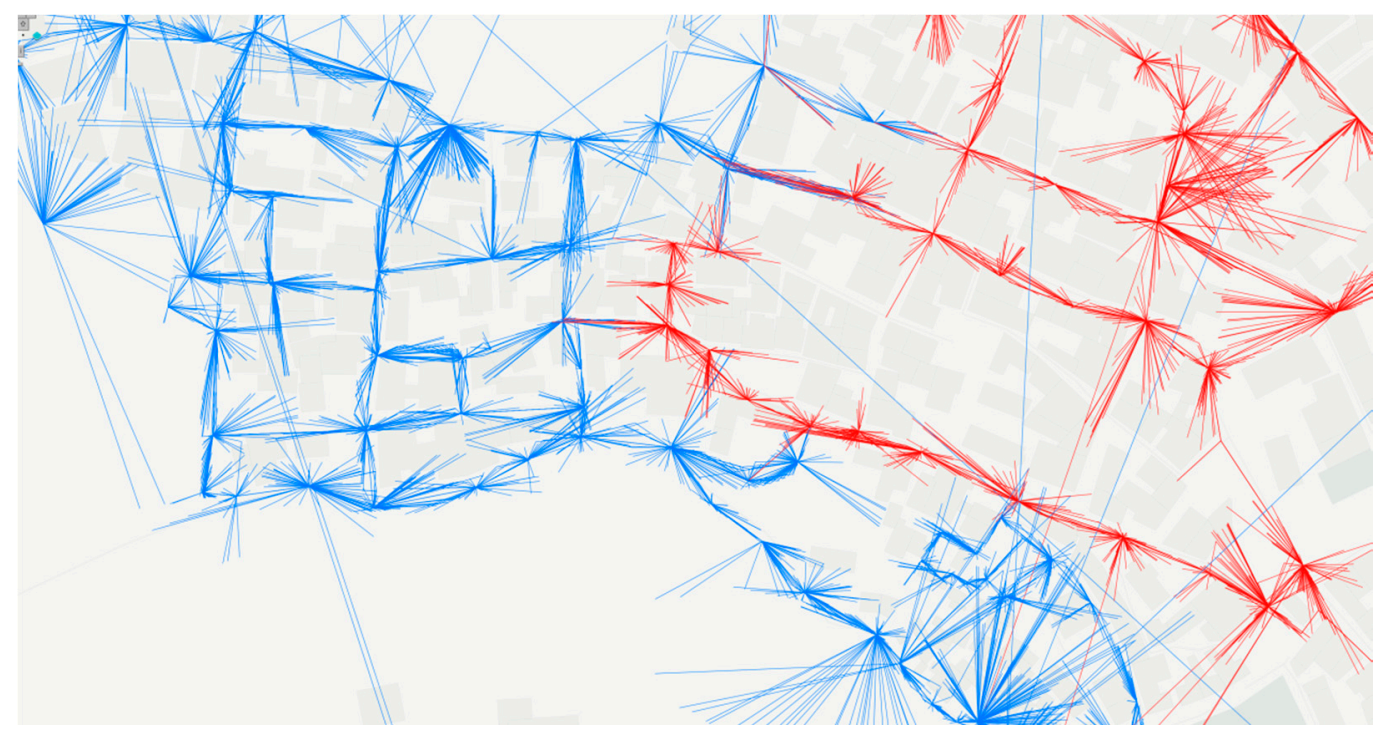

Figure 18. Network of observed features scaled.

For each base station, it is possible to create a buffer polygon that contains all points for which observations have been acquired (excluding detected erroneous observations by applying the maximum distance threshold, based on equipment specifications). These polygons indicate the outer boundary of the points for each observation process. They are created by the convex hull polygon creation function of the PostGIS add-on to PostgreSQL Relational Database Management System (RDBMS). The total of these polygons, once overlaid on each other, provides the coverage of the area that has been the subject of the measurement procedure. Figure 19 clearly represents the coverage pattern and areas that lack observations (compared to Figure 16). Figure 20 highlights areas covered by both operators; thus, it is expected to achieve a higher accuracy level (the yellow area indicates the overlapping observation area for both groups).

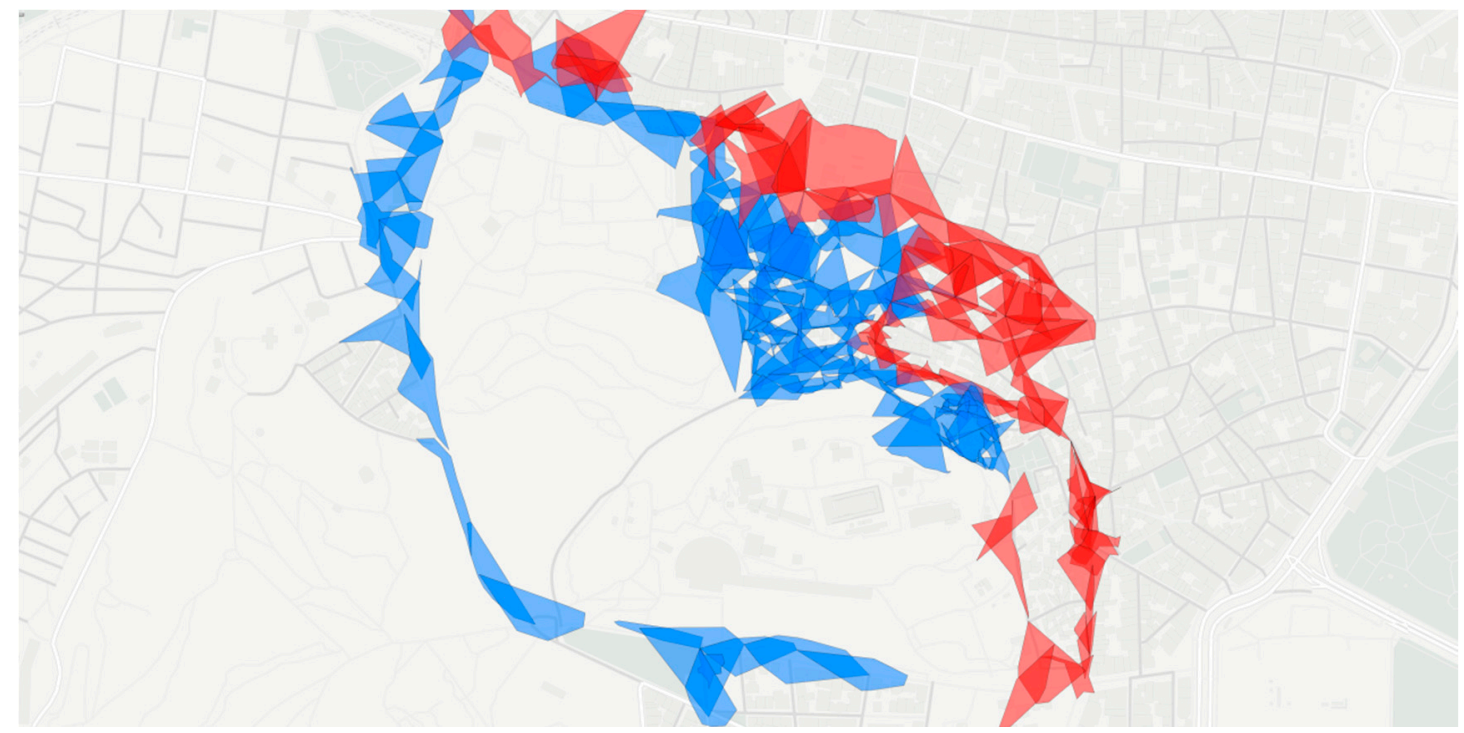

Figure 19. Coverage by process polygon visualization. Different colors indicate different working groups (Group A is indicated in blue and Group B in red). 


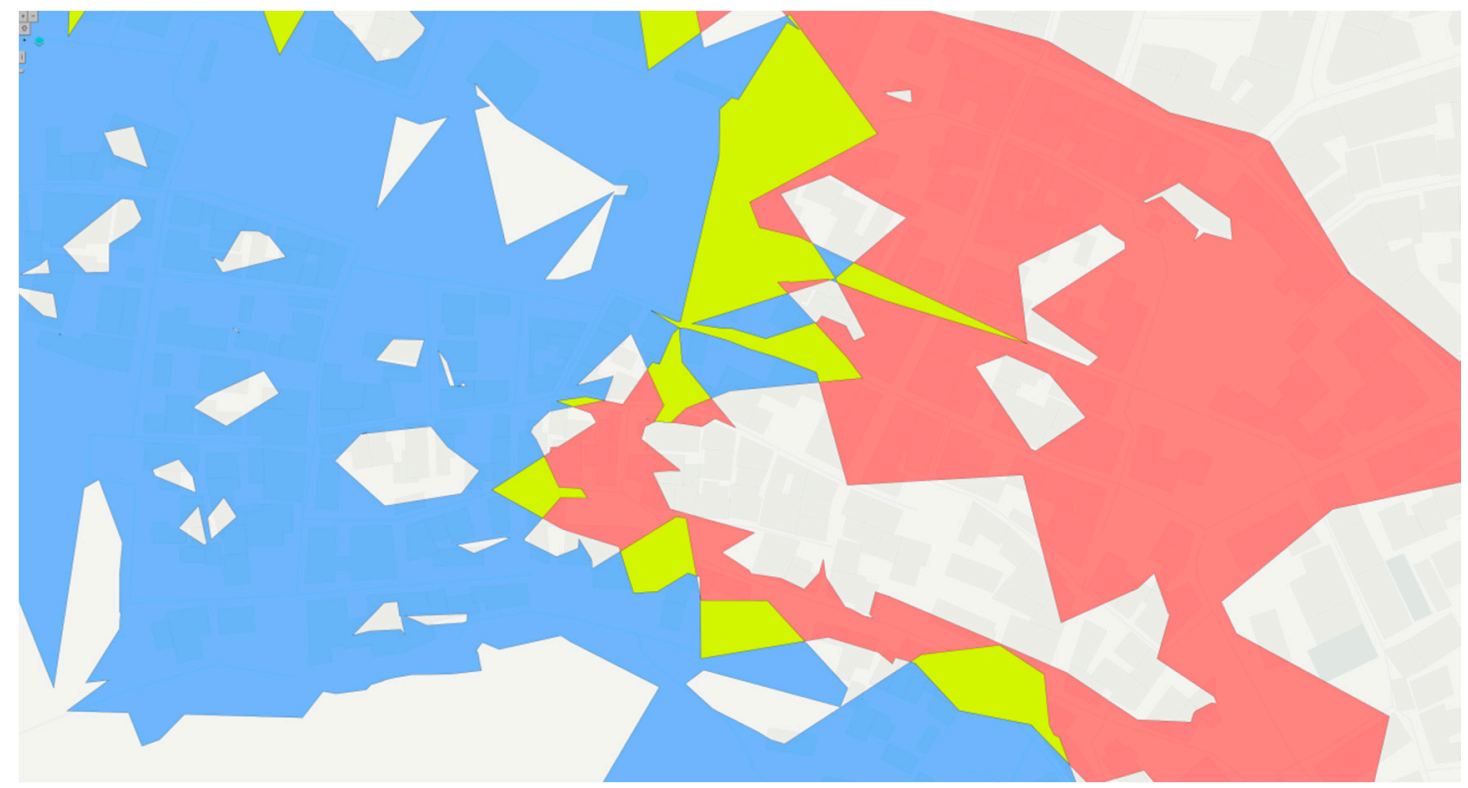

Figure 20. Highlight of the overlapping observation areas by different users.

\section{Conclusions}

There are numerous reasons that indicate and set land surveying measurements as information of high value, addressing the scientific community to manage and reuse it on demand. First and foremost, land surveying measurement acquisition requires most of the resources used in projects of the mapping objective, considering either working hours or technical equipment. Additionally, spatial information collected in the field captures a state of space over the dimension of time that cannot be recollected at a later time. Furthermore, it is obvious that raw measurements contain data that can be combined in the future with other datasets to produce new knowledge. The same does not apply to coordinates and maps created as a product dataset at measurement time.

All of the above reasons have imposed the need for a data model following standards that ensure interoperability. The developed implementation, based on the OGC observation and measurements standard, meets the modeling requirements of the measured information quantities and sets the framework to create repositories and services providing access to information management (save, query), processing and visualization functions. The developed prototype has followed the 'Sensor Observation Service (SOS)' standard as implemented by the $52^{\circ}$ North platform, and the provided XML schemas instantiated the developed model. During this process, a number of considerations came up that exposed the special nature of land surveying measurements in the discussed context.

By developing a model for land surveying observations, we set the critical infrastructure that addresses major considerations of the current information schema, enables alternative data management approaches and introduces novel use case scenarios. The above discussed frame contributes in many ways to a set of emerging benefits, namely:

- Unify scattered data sources and file types under one interoperable data schema.

- Provide access to existing authoritative observations currently unavailable due to the lack of a common measurement model and required services (e.g., national datum land surveying measurements).

- Align land surveying observation schema to the INSPIRE directive that discusses the use of the O\&M model (as motivated by published guidelines [13]).

- Enable data sharing and reusing, thus maximize spent resources' utility.

- Introduce the time dimension to spatial observation datasets, thus motivating the development of error; Earth movement algorithm detection. 
- Provide a critical module to the development of 'Measurement-Based GIS (MBGIS)' systems.

- Motivate data exchange and increase final precision using overlapping observations.

- Develop services that provide real-time land surveying procedure overview, infield data availability and processing.

- Engage shared repositories accessed by professional individuals and public authorities, thus allowing cross-validation and providing access to authoritative official data.

One major difference of land surveying observations for other contexts is the fact that the spatial representation of the feature of interest is not a point entity, but a three-dimensional observation vector. Even though measurements are used to define a posteriori the spatial dimension, the exact feature position is not available at the observation time. That being noted, the data rendering process is not straight forward, but requires an extra processing layer injection between the database SOS service and WMS visualization services.

The case study demonstrated how high volume, real-world observation data can be managed by implementing the developed model in an SOS platform (it should be mentioned though that speed performance issues have been noticed as the database became large, and the $52^{\circ}$ North SOS platform response slowed down). The processing layer managed the positioning information, and the demonstrated WMS visualization service provided raw observation views highlighting aspects of quality and productivity (e.g., coverage, overlapping) in a novel graphical approach (novel in the specific context of land surveying observation depiction).

Information science evolves, and every bit of collected land surveying data acquired, but not saved in a consisted structural way, proves to be the loss of a potential benefit in the aspects of precision, cost of recollection and new data usage methods. Considering the above, along with the fact that measurement-based GIS will really be feasible given a structured modeling of raw observations, the current work suggests an evolving path for land surveying information management, indicates a novel data access-usage scheme and sets the framework to further develop new methodologies to apply on temporal, multi-user collected datasets.

Author Contributions: Sofos I. and Vescoukis V. conceived of and supervised the project. Sofos, Gkegkas and Tsilimantou worked on the analysis and review of the OGC standards and implementations. Sofos I. and Gkegkas A. worked to produce the developed model. Sofos I. and Tsilimantou E. worked on the process of data collection. Sofos I. and Tsilimantou E. developed the XML schemas. Sofos I. and Vescoukis V. developed the software and built the database infrastructure. Sofos I. Vescoukis V. and Gkegkas A. wrote the paper.

Conflicts of Interest: The authors declare no conflict of interest.

\section{References}

1. Agrawal, R.; Evfimievski, A.; Srikant, R. Information sharing across private databases. In Proceedings of the 2003 ACM SIGMODInternational Conference on Management of Data, San Diego, CA, USA, 9-12 June 2003.

2. Özyer, T.; Kianmehr, K.; Tan, M. Recent Trends in Information Reuse and Integration; Springer: Berlin, Germany, 2011.

3. Fienberg, S.E.; Martin, M.E.; Straf, M.L. Sharing Research Data; National Academies: Washington, DC, USA, 1985.

4. Sieber, J.E.; Trumbo, B.E. (Not) giving credit where credit is due: Citation of data sets. Sci. Eng. Ethics 1995. [CrossRef]

5. Buyong, T.; Werner, K.; Frank, A.U. A conceptual model of measurement-based multipurpose cadastral systems. J. Urban Regional Inf. Syst. Assoc. 1991, 3, 35-49.

6. Goodchild, M.F. Measurement-based GIS. In Proceedings of the International Symposium on Spatial Data Quality, Hong Kong, China, 18-20 July 1999.

7. Navratil, G.; Franz, M.; Pontikakis, E. Measurement-based GIS revisited. In Proceedings of the 7th AGILE Conference on Geographic Information Science, Heraklion, Greece, 29 April-1 May 2004.

8. Leung, Y.; Ma, J.-H.; Goodchild, M.F. A general framework for error analysis in measurement-based GIS Part 1: The basic measurement-error model and related concepts. J. Geogr. Syst. 2004, 6, 325-354. [CrossRef] 
9. Vranić, S.; Jurakić, G.; Matijević, H. Modelling and dissemination of land survey data. In Proceedings of the INGEO 2014-6th International Conference on Engineering Surveying, Prague, Czech, 3-4 April 2014.

10. ISO 19152:2012, Geographic Information-Land Administration Domain Model. Available online: http:/ / www.iso.org/iso/catalogue_detail.htm?csnumber=51206 (accessed on 23 October 2016).

11. Lemmen, C.; Van Oosterom, P.; Bennett, R. The land administration domain model. Land Use Policy 2015, 49, 535-545. [CrossRef]

12. Parliament, European and Union, Council of the European. Directive 2007/2/EC of the European Parliament and of the Council of 14 March 2007 Establishing an Infrastructure for Spatial Information in the European Community (INSPIRE). Available online: http:/ / eur-lex.europa.eu/legal-content/EN/ALL/?uri=CELEX\% 3A32007L0002 (accessed on 27 February 2017).

13. INSPIRE Cross Thematic Working Group on Observations \& Measurements. D2.9 Draft Guidelines for the Use of Observations \& Measurements and Sensor Web Enablement-Related Standards in INSPIRE Annex II and III Data Specification Development. Available online: http://inspire.ec.europa.eu/documents/Data_ Specifications/D2.9_O\&M_Guidelines_v2.0rc3.pdf (accessed on 27 February 2017).

14. Na, A.; Priest, M. Open GIS Sensor Observation Service Implementation Specification; Open Geospatial Consortium Implemention Specifications: Wayland, MA, USA, 2006. Available online: https:/ / portal.opengeospatial. org/files/?artifact_id=26667 (accessed on 27 February 2017).

15. OGC®Sensor Observation Service Interface Standard. 2012. Available online: https://portal.opengeospatial. org/files/?artifact_id=47599 (accessed on 23 October 2016).

16. Van Oosterom, P.J.M.; Lemmen, C.H.J.; Uitermark, H.T.; Boekelo, G.; Verkuijl, G. Land administration standardization with focus on surveying and spatial representations. In Proceedings of the ACMS Annual Conference 2011, San Diego, CA, USA, 7-12 July 2011.

17. Kandawasvika, A.; Reinhardt, W. Concept for interoperable usage of multi-sensors within a landslide monitoring application scenario. In Proceedings of the 8th AGILE Conference on GIScience, Estoril, Portugal, 26-28 May 2005.

18. Sofos, I.; Vescoukis, V.; Tsakiri, M. Applications of volunteered geographic information in surveying engineering: A first approach. In AGILE 2015; Springer: Berlin, Germany, 2015.

19. Open Geospatial Consortium. Available online: http://www.opengeospatial.org/ (accessed on 23 October 2016).

20. Open Geospatial Consortium History. Available online: http://www.opengeospatial.org/ogc/historylong (accessed on 23 October 2016).

21. Open Geospatial Consortium Members. Available online: http://www.opengeospatial.org/ogc/members (accessed on 23 October 2016).

22. OGC-SWE-DWG. Available online: http://www.opengeospatial.org/projects/groups/sensorwebdwg (accessed on 23 October 2016).

23. Open Geospatial Consortium. OGC Sensor Web Enablement Architecture. Available online: https://portal. opengeospatial.org/files/?artifact_id=29405 (accessed on 27 February 2017).

24. BIPM, IEC; The International Vocabulary of Metrology-Basic and General Concepts and Associated Terms (VIM), JCGM. 2008. Available online: http://www.bipm.org/utils/common/documents/jcgm/JCGM_200_ 2012.pdf (accessed on 27 February 2017).

25. Open Geospatial Consortium. Observations and Measurements-Part 1-Observation Schema. 2007. Available online: http://portal.opengeospatial.org/files/?artifact_id=22466 (accessed on 27 February 2017).

26. Open Geospatial Consortium. OGC Abstract Specification, Geographic Information-Observations and Measurements. Available online: https:/ / portal.opengeospatial.org/files/?artifact_id=41579 (accessed on 27 February 2017).

27. ISO 19101:2014, Geographic Information—Reference Model. Available online: http://www.iso.org/iso/iso_ catalogue/catalogue_tc/catalogue_detail.htm?csnumber=59164 (accessed on 27 February 2017).

28. ISO 19109:2015, Geographic Information—Rules for Application Schema. Available online: http://www.iso.org/ iso/iso_catalogue/catalogue_ics/catalogue_detail_ics.htm?csnumber=59193 (accessed on 27 February 2017).

29. Bröring, A.; Echterhoff, J.; Jirka, S.; Simonis, I.; Everding, T.; Stasch, C.; Liang, S.; Lemmens, R. New generation sensor web enablement. Sensors 2011, 11, 2652-2699. [CrossRef] 
30. Roope, T.; Mikko, V.; Tero, K.; Jukka, A.P.; Tarja, R. Meteorological and aviation weather open data implementation utilizing Open Geospatial Consortium (OGC) standards. In Proceedings of the FOSS4G Europe Como 2015, Como, Italy, 15-17 July 2015.

31. Open Geospatial Consortium. OGC ${ }^{\circledR}$ WaterML 2.0: Part 1-Timeseries. 2012. Available online: http:/ / www. waterml2.org/10-126r2_10-126r2_WaterML_2.0_Candidate_Standard.pdf (accessed on 27 February 2017).

32. Jirka, S.; Bröring, A.; Stasch, C. Applying OGC sensor web enablement to risk monitoring and disaster management. In Proceedings of the GSDI 11 World Conference, Rotterdam, The Netherlands, 15-19 June 2011.

33. Chen, N.; Di, L.; Yu, G. A flexible geospatial sensor observation service for diverse sensor data based on Web service. ISPRS J. Photogramm. Remote Sens. 2009, 64, 274-282. [CrossRef]

34. Zhou, L.; Chen, N.; Yuan, S.; Chen, Z. An efficient method of sharing mass spatio-temporal trajectory data based on cloudera impala for traffic distribution mapping in an urban city. Sensors 2016, 16, 1813. [CrossRef] [PubMed]

35. Zhou, L.; Chen, N.; Chen, Z.; Xin, C. ROSCC: An efficient remote-sensing observation sharing method based on cloud computing for soil moisture mapping in precision agriculture. IEEE J. Sel. Top. Appl. Earth Obs. Remote Sens. 2016, 9, 5588-5598. [CrossRef]

36. Cuzzocrea, A.; Song, I.; Davis, K.C. Analytics over large-scale multidimensional data: The big data revolution. In Proceedings of the ACM 14th International Workshop on Data Warehousing and OLAP, Glasgow, UK, 28 October 2011.

37. Ghilani, C.D.; Wolf, P.R. Elementary Surveying: An Introduction to Geomatics, 13th ed.; Prentice Hall: Upper Saddle River, NJ, USA, 2013.

(C) 2017 by the authors. Licensee MDPI, Basel, Switzerland. This article is an open access article distributed under the terms and conditions of the Creative Commons Attribution (CC BY) license (http:/ / creativecommons.org/licenses/by/4.0/). 